\title{
Proposta de um Arcabouço Metodológico para a Autoria de Conteúdo em Ambientes Imersivos de Ensino
}

\author{
Leander de Oliveira, PPGComp, FURG, leanderdeoliveira@gmail.com \\ Danúbia Bueno Espíndola, PPGComp, FURG, danubiaespindola@furg.br \\ Regina Barwaldt, PPGComp, FURG, reginabarwaldt@furg.br \\ Marilia Abrahão Amaral, PPGTE, UTFPR, marilia.utfpr@gmail.com \\ Silvia Silva da Costa Botelho, PPGComp, FURG, silviacb.botelho@gmail.com
}

\begin{abstract}
Resumo. O presente artigo tem como objetivo a busca de métodos que facilitem e difundam o uso de ambientes imersivos através da convergência de três conceitos: mundos virtuais tridimensionais, imersão e a representação do aluno por meio de um avatar digital. O levantamento acerca do ferramental utilizado na autoria de conteúdos para ambientes imersivos de ensino levaram ao reconhecimento das etapas para a criação destes ambientes e culminaram na proposta de um arcabouço metodológico de caráter genérico para a autoria. Esta proposta foi aplicada a um desenvolvimento experimental como forma de reconhecimento de suas possibilidades e abrangência.
\end{abstract}

Palavras - Chave: Ambientes Imersivos de Ensino, Arcabouço Metodológico, Autoria.

\section{A Proposal for Methodological Framework of Content Authoring in Immersive Learning Environments}

Abstract. This paper aims to search for methods that facilitate and disseminate the use of immersive environments through the convergence of three concepts: threedimensional virtual worlds, immersion and representation of the student through a digital avatar. The survey about the tools used for content authoring in immersive learning environments have led to the recognition of the steps for creating these environments and culminated in the proposal of a methodological framework with a general nature for authorship. The proposal was applied to an experimental development to recognize its possibilities and scope.

Keywords: Immersive Learning Environments, Methodological Framework, Authorship.

\section{Introdução}

A utilização de tecnologias da informação e comunicação no apoio às metodologias de ensino-aprendizagem presenciais ou à distância, não são apenas inovações que surgem aos processos educativos atualmente, e sim demandas cotidianas para um ensino interativo. Embora exista uma crescente disseminação dos ambientes virtuais de aprendizagem (AVAs) bem como de objetos de aprendizagem (OAs), é notável a falta de ferramentas que proporcionem autoria na geração de conteúdos multimídia interativos, bem como a apropriação das tecnologias da informação e comunicação por parte dos professores.

Neste contexto, este trabalho busca debater meios para o desenvolvimento intuitivo de materiais digitais para que professores tornem-se desenvolvedores de seus conteúdos e não apenas meros utilizadores de ferramentas computacionais voltadas a aplicações específicas. Os Ambientes Imersivos de Ensino/Aprendizagem compreendidos por metaversos e mundos virtuais, denotam uma possibilidade para o envolvimento do aprendiz de maneira diferenciada (usando visualização 3D e interação) através de sua imersão em ambientes que recriam salas de aula, laboratórios, congressos 
e diferentes contextos a serem explorados (Lorenzo et. al., 2012; Viegas, 2012; Nascimento e Spilker, 2012).

A autoria de conteúdos e de materiais para Ambientes Imersivos de Ensino/Aprendizagem através de ferramentas de desenvolvimento é complexa e de difícil utilização. Na maioria das vezes, os conteúdos são desenvolvidos por programadores e não possuem recursos para serem adaptados de acordo com a aplicação e contexto do professor. A necessidade de desenvolvimento orientado pelo professor demanda muitas horas para a criação de conteúdos 3D interativos e ocasionam muitas vezes a desistência do desenvolvimento de conteúdos mais elaborados (Khot e Choppella, 2011).

Outro ponto crucial quando se objetiva desenvolver um conteúdo 3D interativo ou um objeto de aprendizagem é a organização da maneira como o conteúdo será apresentado para o estudante/aprendiz, ou seja, a falta de controle da interface sobre o usuário. O desenvolvimento e utilização de um roteiro digital (ou storyboard) para modelagem da lógica do conteúdo imersivo, contextualizando os materiais e a maneira como eles serão tratados em um AVA imersivo, é de suma importância para o sucesso e efetividade do uso de conteúdos 3D interativos. Considerando que um objeto de aprendizagem esteja sendo desenvolvido em um ambiente imersivo, é necessário pensar como um dos desafios o comportamento não linear absoluto ${ }^{1}$ do avatar, ou seja, a navegação para o avatar deve possuir uma sequencialidade para que o aluno se sinta motivado a continuar explorando este ambiente.

Recursos que tratem da ordenação de conteúdos de maneira não diretiva, considerando a abstração de determinados temas e da necessidade de reflexão e análise visual de materiais para uma melhor compreensão são de suma importância para a ordenação de passos no AVA. Aplicações que permitam ao estudante, professor ou desenvolvedor expor todas as suas ideias, conceitos, conteúdos por meio de diferentes tipos de materiais e mídias (imagens, diagramas, sons, vídeos, músicas, dentre outros) e posterior a isso criar uma relação organizacional entre estes materiais são alguns dos objetivos deste estudo. Esse processo permite ao usuário compreender o conteúdo de maneira síncrona, considerando estágios e etapas para o aprendizado.

Entre os trabalhos que tem como tema a definição de materiais educacionais com contexto tecnológico, destaca-se o trabalho de Souza et. al. (2013) que descreve uma abordagem de autoria que trata do desenvolvimento sem considerar a não linearidade presente nos ambientes imersivos. Outro destaque é o Learning Design, descrito por Conole (2008), que trata do design para a criação de conteúdo digital por meio de diversas abstrações de maneira mais ampla em comparação a abordagem descrita por Souza et. al. (2013) que não abrange os ambientes imersivos. Mesmo citando a existência e as possibilidades que os ambientes imersivos trazem para o processo de ensino, Conole (2008) não trata diretamente sobre eles em sua pesquisa.

O foco desta pesquisa é a proposição de uma solução para autoria e desenvolvimento de conteúdos para os ambientes imersivos de ensino, considerando a necessidade de sequencialidade na apresentação de conteúdos. A apresentação desta proposta será dada por meio do levantamento de um arcabouço metodológico descrito nas seções seguintes.

\section{Ambientes Imersivos de Ensino}

Ao passo em que cresce a demanda por estruturas diferenciadas no processo de ensino e aprendizagem, mais a tecnologia vem sendo empregada nesta constante busca. A virtualização de ambientes é uma alternativa que traz consigo inúmeras possibilidades inovadoras e que podem modificar parâmetros, como por exemplo: diferenciações na 
motivação do aluno; possibilidade para o processo de aprendizagem ocorrer com os indivíduos geograficamente distanciados; a construção coletiva de conhecimento em ambientes específicos para tais fins; dentre outros.

Em uma definição básica, o ensino a distância pode ser compreendido como uma busca pela aprendizagem ocorrendo com liberdade institucional, de espaço e tempo. Mas ainda existe um engessamento neste processo de aprendizagem digital uma vez que os estudantes ainda se mantêm presos às diretrizes de ensino de instituições de ensino e aos prazos e horários de tarefas. Peters (2006) afirma que a partir do ponto em que se compreendam todas as possibilidades fornecidas pela educação informatizada, muitas mudanças deverão ocorrer no processo de ensino.

McGonigal (2011) fala em sua obra, intitulada Reality is Broken, sobre a crescente quebra dos parâmetros reais nas interações e vivências humanas. Ela trata essencialmente sobre a crescente fuga social para os mundos virtuais por meio dos mundos e jogos eletrônicos e propõe o uso de técnicas de Game Design na busca de uma evolução social em uma diferenciada gama de áreas de aplicação. Sua tese é facilmente aplicada à área educacional considerando as possibilidades citadas anteriormente e a busca por ambientes que permitam aos estudantes a vivência e interação com o uso de meios virtuais.

Neste ponto, analisando as afirmações de Peters (2006) em convergência as de McGonigal (2011) temos os ambientes imersivos de ensino como um interessante foco de pesquisa, pois estes permitem justamente a interação de indivíduos (representados por avatares) em ambientes 3D desenvolvidos para recriar o mundo real (representados pelos metaversos) com o foco em objetivos educacionais possibilitando o não engessamento das interações dos aprendizes ao utilizarem ambientes virtuais de aprendizagem (AVAs).

Os ambientes imersivos de ensino tratados nesta pesquisa são descritos detalhadamente em Schaf (2011) por meio de três características:

- A definição de Imersão, com espaços onde o usuário tem a sua noção física de corpo modificada por meio de um ambiente virtual onde reconhece comportamentos naturais o que o leva a agir de tal maneira. Os tipos de imersão podem ser sensorial, motora, cognitiva, emocional, espacial e psicológica;

- A definição de Mundos Virtuais Tridimensionais, que aborda os ambientes tridimensionais criados com o objetivo de simular o mundo real. Tais ambientes são chamados de metaversos por recriarem as características do universo estudado em ambientes virtuais. Schlemmer e Backes (2008) definem os metaversos como:

"tecnologia que se constitui no ciberespaço e se "materializa" por meio da criação de Mundos Digitais Virtuais em 3D (MDV3D), no qual diferentes espaços para o viver e conviver são representados em 3D, propiciando o surgimento dos “mundos paralelos" contemporâneos" (Schlemmer e Backes, 2008);

- As definições de Avatares são compreendidas por diferentes âmbitos de estudo, mas no presente trabalho pode ser considerado um avatar uma representação humana por meios digitais. Esta representação passa pela personalização do usuário conforme a maneira que pretende ser reconhecido, o que traz diversas implicações psicológicas, motivacionais e fatores ainda em estudo (Fragoso e Rosário, 2008).

Algumas pesquisas estudam o uso de tecnologias e técnicas de Mundos Virtuais Tridimensionais, Imersão e Avatares no processo de ensino. Estas propostas abordam ferramentas e tecnologias para o desenvolvimento de elementos e ambientes. A seção a seguir aborda um levantamento de soluções tecnológicas para este tipo de abordagem. 


\section{Análise das Ferramentas}

Os estudos iniciaram com o reconhecimento e definição das etapas necessárias para a criação de conteúdos que trazem a imersão como característica. Para este propósito várias ferramentas, utilizadas no desenvolvimento de ambientes imersivos, passaram por análise. Dentre estas ferramentas, estão o servidor OpenSimulator ${ }^{2}$, o viewer Singularity ${ }^{3}$, o software para animação Scratch for OpenSim ${ }^{4}$, e os softwares Celtx ${ }^{5}$ e CmapTools ${ }^{6}$, todos descritos nesta seção.

A utilização de ambientes imersivos no contexto de ensino utiliza o conceito de metaversos (meta universos) para seu desenvolvimento e disponibilidade. Dentre as ferramentas existentes que contemplam os metaversos, destacam-se os servidores Second $\mathrm{Life}^{7}$ (SL) e OpenSimulator (OS). Tarouco et. al. (2012) faz um estudo comparativo entre estas tecnologias e aponta fatores sobressalentes do OpenSimulator em relação ao Second Life, dentre eles o fato de o OS ser uma ferramenta open source e permitir a instalação do servidor na própria máquina do usuário. Ter o servidor instalado na própria máquina permite a utilização do metaverso sem a necessidade de considerar taxas de banda para o acesso ou demais tributos cobrados pela utilização, como acontece no Second Life. Outra questão importante levantada é a restrição etária aos usuários do Second Life, o que não existe no OpenSimulator, uma vez que o conteúdo pode ser controlado de maneira mais efetiva por configurações e instalações que permeiam objetivos especificamente educacionais. Além dos fatores apontados, o fato de ser uma ferramenta de código aberto faz com que o OpenSimulator seja utilizado em inúmeras aplicações com diferentes finalidades, como nos trabalhos de Nunes et. al (2013), Avila et. al. (2013), Voss et. al. (2013), Mota et. al. (2012), dentre muitos outros.

Por meio da pesquisa de Nunes et. al. (2013), que realizou um estudo comparativo acerca de diferentes viewers (Imprudence, Firestorm, Hippo, Phoenix, Singularity, Cool, VL e Kokua) para acesso ao servidor OpenSimulator, foi observado que o software Singularity reúne as melhores funcionalidades em relação aos demais. São descritos testes feitos com estes oito sistemas e, apesar de exigir mais processamento como aspecto negativo, o viewer Singularity apresenta bons resultados na comparação com os demais por permitir a importação e visualização de objetos de diferentes repositórios e objetos multimídias, ter licença open source e ser multiplataforma.

Na ferramenta Scratch for OpenSim, voltada à programação visual, o usuário define ações arrastando abas com as funções desejadas para montar seu código fonte, conforme descreve Avila et. al. (2013). A ferramenta foi criada com base no software Scratch e torna a programação simples de ser compreendida e implementada, o que ajuda a disseminar o uso de ambientes que exigem um desenvolvimento com maior complexidade. Apesar de algumas limitações acerca de possibilidades de desenvolvimento, o Scratch for OpenSim permite a implementação fácil de muitas ações para os objetos nos metaversos do OpenSimulator. Isto significa, que o Scratch for OpenSim poderá prover recursos para implementação da interatividade e movimento dos objetos do ambiente imersivo.

Para a parte da definição inicial do ambiente, duas ferramentas foram testadas: o Celtx e o CmapTools. O software Celtx, por tratar de roteirização para histórias lineares, não alcançou as necessidades esperadas. Por sua vez, a ferramenta CmapTools possibilita a organização de conteúdos por meio de diagramas bidimensionais conhecidos como mapas mentais ou mapas conceituais e foi proposto nos anos 70 pelo pesquisador norte-americano Joseph Novak (Pereira, 2009). A notação destes mapas é constituída por nodos que podem representar informações, conceitos e conteúdos de 
diversas naturezas. Tais nodos são representados por caixas que podem ser interligadas por frases em arcos que fazem o papel de ligação entre estes nodos. Sendo assim, é aplicável a utilização desta ferramenta em roteirizações para definir o ambiente, avatares, objetos e a interação entre eles.

Pelo fato do ambiente em um metaverso ser absolutamente livre ao avatar, ou seja, este pode explorar o espaço de maneira totalmente não linear, sem respeitar um roteiro pré-estabelecido, pode haver alguma restrição na utilização desta ferramenta. Utilizando mapas conceituais e considerando todas as possibilidades de interação do avatar com o ambiente, pode ocorrer de o desenvolvedor acabar representando um número muito grande de ações e interações, tomando proporções muito elevadas e por fim dificultando as definições necessárias. Neste ponto observa-se a necessidade de um cuidado especial por parte do desenvolvedor junto à equipe pedagógica do conteúdo.

Ao fim da análise das ferramentas, ficam esclarecidas as etapas pelas quais passa o processo de autoria de um ambiente imersivo de ensino. A próxima seção descreve a proposta de um arcabouço metodológico envolvendo as etapas genéricas identificadas.

\section{Arcabouço Metodológico}

Por meio da análise do levantamento de ferramentas utilizadas no processo de autoria, observa-se o reconhecimento de algumas etapas necessárias para que o desenvolvedor/professor exponha conceitos, conteúdos e sequência de navegação no ambiente de maneira eficiente e intuitiva. Sendo assim, a partir do levantamento das ferramentas descritas é possível propor um arcabouço metodológico que abranja tais passos e permita a fácil implantação dos conceitos (materiais) que o professor precisa expor e a intuitiva indicação de sequencialidade que o aluno deve ter para compreender tais conteúdos.

O desafio para prover o desenvolvimento intuitivo ao professor fornecendo a autoria no processo de disponibilização de conteúdo 3D para ambientes imersivos esbarra na definição de um modelo para esta ferramenta que atenda aos seguintes requisitos:

Definição de objetos 3D (avatar, cenários, mobílias, etc); Descrição de ações dos objetos (andar, abrir, fechar, enviar, receber); Definição do fluxo de navegação e interação entre os objetos para a sequencialidade da aula no ambiente; Inserção de conteúdos multimídias (textos, áudios, apresentações, planilhas, vídeos, animações, etc).

Ao passo em que estes requisitos foram identificados, torna-se possível propor um conjunto genérico de práticas por meio de etapas a serem seguidas para a autoria de materiais educacionais imersivos. A Figura 1 trata do arcabouço metodológico proposto.

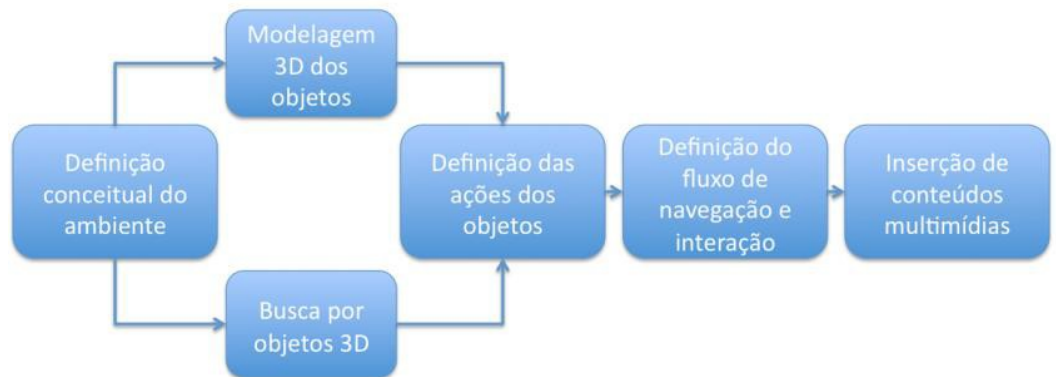

Figura 1 - Arcabouço metodológico proposto para a autoria de material educacional imersivo.

As etapas compreendidas na Figura 1 iniciam com a definição conceitual do ambiente, em que o professor deve pensar seu conteúdo de maneira ampla e abrangente, como por exemplo, em quais espaços os avatares poderão interagir com os conteúdos 
como essa interação deverá ocorrer, quais objetos estarão presentes para apresentar estes conteúdos, dentre outros fatores. A segunda etapa trata da criação ou modelagem dos objetos, essa modelagem pode ser suprida pela busca de objetos prontos em repositórios online $^{8}$. A terceira etapa deve tratar do comportamento e aparência dos objetos que foram reunidos anteriormente de acordo com as necessidades abordadas na definição conceitual do ambiente. Em seguida, o fluxo de navegação baseado na roterização do conteúdo deve ser definido de forma a sequencializar as interações no ambiente para que o avatar tenha uma rotina de navegação que acompanhe os estágios de aprendizagem. Por fim os conteúdos devem ser inseridos, organizados e distribuídos no ambiente.

Considerando a proposta em questão, a seção a seguir visa demonstrar o uso do modelo descrito utilizando o ferramental abordado na seção anterior.

\section{Teste de Uso}

Como aplicação do arcabouço metodológico proposto, foram instalados os softwares descritos anteriormente e alguns testes foram desenvolvidos para o estudo da efetividade da proposta e da disponibilidade de recursos para sua utilização.

A primeira etapa para os testes envolveu a definição conceitual do ambiente, sendo assim, foi desenvolvido um roteiro de um possível objeto de aprendizagem para AVA, de um conteúdo específico, a fim de definir a sequencialidade no ambiente imersivo para apropriação do conteúdo pelo aluno. Foi utilizado o software CmapTools para este propósito. O conteúdo a ser trabalhado teve como tema Inclusão Digital, mais precisamente, os conhecimentos básicos sobre hardware. Foram elaborados dois mapas conceituais para o ambiente em questão. A Figura 2 mostra o diagrama que trata das interações possíveis no cenário, onde o usuário deve estar inserido como ponto de partida no ambiente. Com este mapa conceitual, obteve-se um modelo que define a estrutura de ações genéricas dentro de um ambiente imersivo. Isto significa que o modelo descrito serve para qualquer aplicação onde há um avatar representando o aluno na navegação em ambientes imersivos.

Em seguida, foi desenvolvido o roteiro acerca das interações possíveis para a navegação no ambiente envolvendo o conteúdo básico de hardware, como mostra a Figura 3.

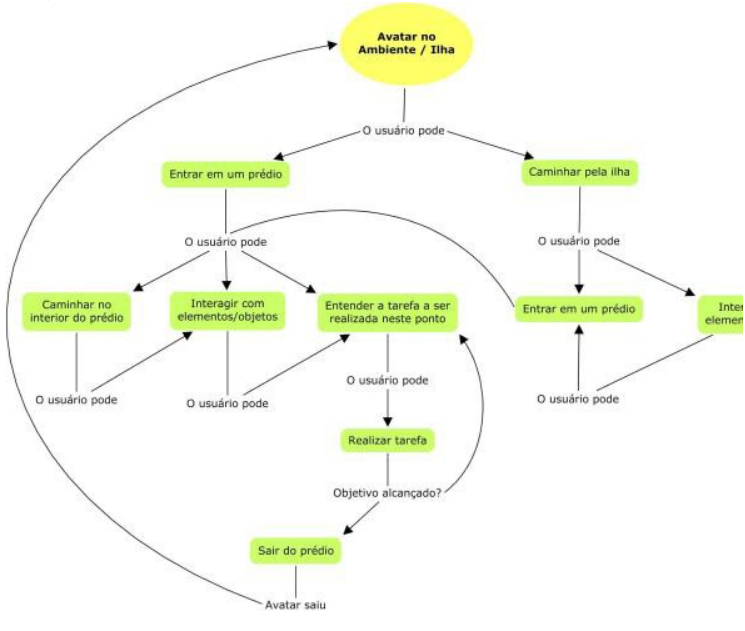

Figura 2 - Roteirização das possíveis ações do objeto avatar em ambiente imersivo utilizando mapa conceitual.

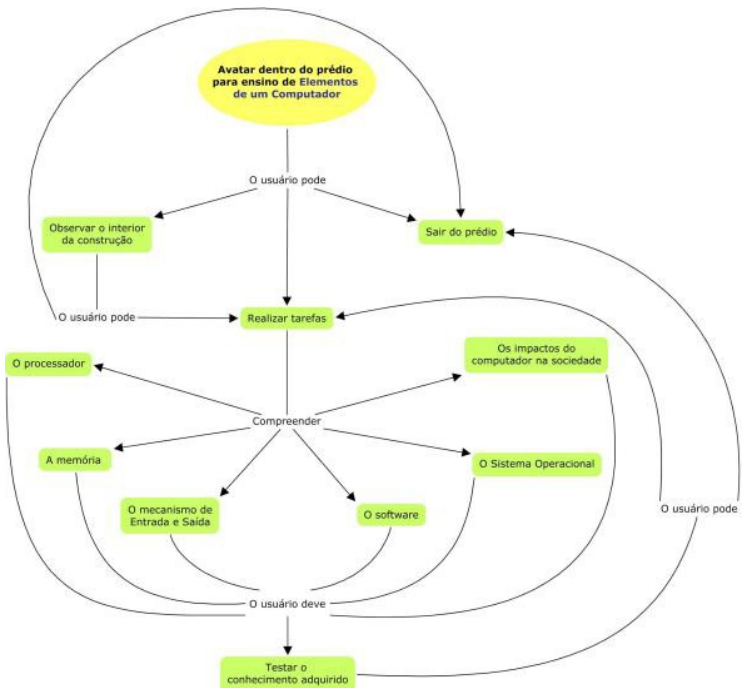

Figura 3 - Roteirização das possíveis ações do objeto avatar em ambiente imersivo com conteúdo básico sobre hardware. 
Algumas possibilidades de interação do avatar foram consideradas neste mapa conceitual, mas outras podem ser previstas neste ponto do desenvolvimento do ambiente. Neste momento da análise, já podem ser observadas as dificuldades no uso desta ferramenta para roteirizações não lineares, visto que toda a modelagem do ambiente envolveria um grande número de mapas conceituais como este. Quando a abordagem for um tema com um domínio amplo de possibilidades, torna-se complexo aplicar esta ferramenta para o desenvolvimento.

Após a etapa das definições iniciais, o servidor OpenSimulator foi instalado e configurado para servir como base para implementação do ambiente. Logo em seguida o viewer Singularity também passou por este processo para possibilitar a visualização do metaverso hospedado no OpenSimulator. Em seguida, a ferramenta Scratch for OpenSim foi instalada para a etapa de definição das ações de interação dos objetos e elementos.

Com todos os softwares necessários disponíveis, um objeto foi criado no ambiente por meio do viewer Singularity e logo em seguida manipulado para ficar com a aparência de uma parede. O próximo passo testou a utilização do Scratch for OpenSim para a animação do objeto criado. A ferramenta é de fácil utilização e pessoas com pouca compreensão de programação devem conseguir utilizá-la. A Figura 4 mostra o código exemplo desenvolvido em que, conforme a aproximação de um avatar, o objeto imprime textos na tela a cada segundo.

Depois de implementada a ação desejada, o código deve ser migrado para um script associado ao objeto e apontado como ativo para que possa ser executado nas interações. A Figura 5 mostra a ação do script gerado anteriormente sobre o objeto criado no metaverso.

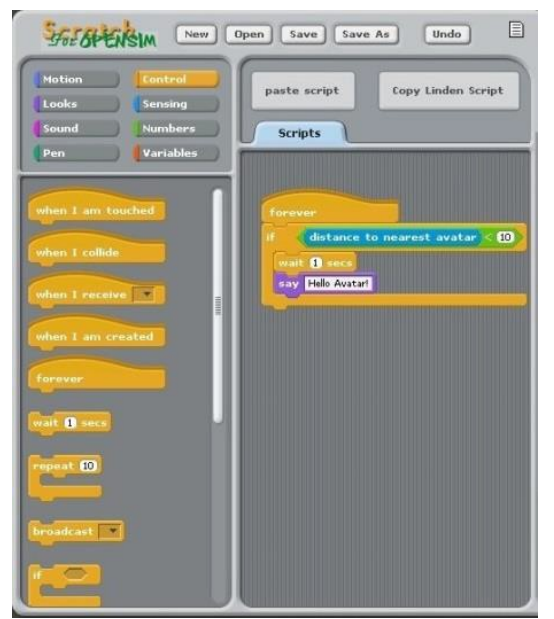

Figura 4 - Implementação de ações de objetos

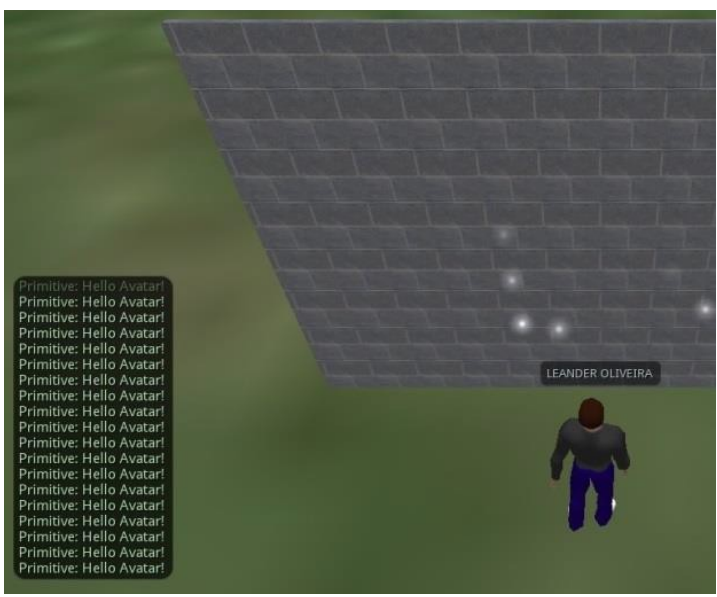

Figura 5 - Script com as ações desenvolvidas no Scratch for OpenSim executando sobre o objeto. utilizando Scratch for OpenSim.

Demais testes foram aplicados neste mesmo contexto e algumas interações puderam ser modeladas e programadas por meio do Scratch for OpenSim.

Diversos objetos, construções e outros elementos podem ser encontrados prontos em repositórios online. Um destes repositórios é o OpenSim Creations ${ }^{9}$, utilizado no teste em questão. Após a busca e localização do objeto necessário, seu comportamento foi alterado para a execução de tarefas pertinentes ao objetivo do ambiente.

Por fim a coleção de elementos coletados, criados e manipulados nas etapas anteriores foi ordenada e inserida no ambiente buscando criar uma indicação sequencial 
dos quadros que devem ser visitados para a interação dos avatares alunos. A Figura 6 mostra o resultado final do ambiente experimental.

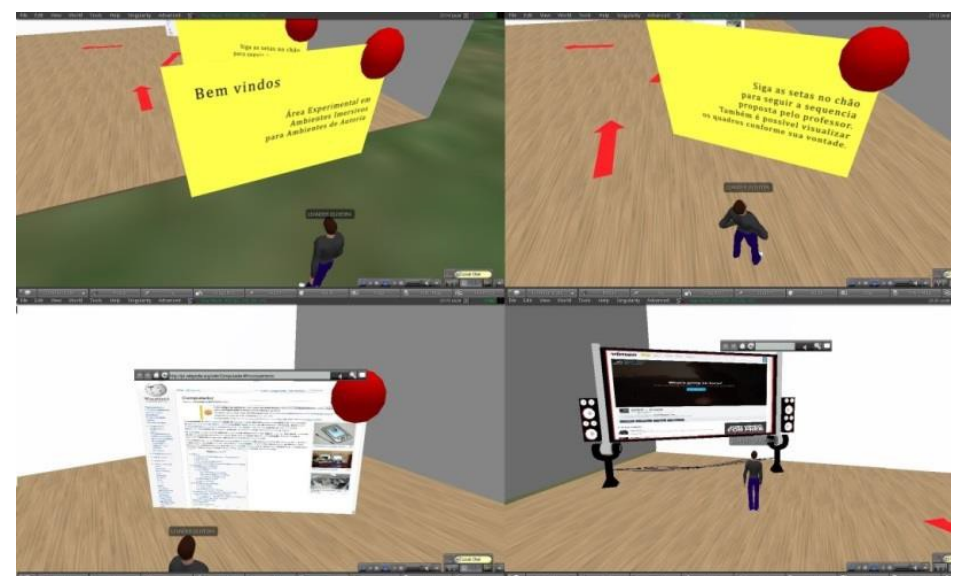

Figura 6 - Avatar interagindo com o ambiente experimental.

A Figura 6 mostra telas de alguns quadros com conteúdos e as setas que guiam o estudante pelo ambiente. Um texto da Wikipédia ${ }^{10}$ é apresentado em uma das imagens, o que serviu como forma de compreender a maneira de acessar conteúdo externo ao ambiente imersivo. Outra interface mostra o avatar assistindo a um vídeo sobre processadores no site Vimeo ${ }^{11}$. Outros textos também aparecem nas imagens, demonstrando a possibilidade de inserção de diversos tipos de conteúdo por meio das ferramentas pesquisadas.

\section{Análises Finais}

A compreensão do estado da arte acerca dos Ambientes Imersivos com foco educacional demonstra que ainda existem possibilidades inexploradas e desafios complexos para o efetivo uso deste tipo de ambiente. A partir do momento em que o usuário/estudante interage com o conteúdo, bem como, o professor se torna autor de seu ambiente, a motivação e as possibilidades de compreensão devem aumentar a níveis consideráveis.

A busca por ferramentas e metodologias que auxiliem a popularização dos ambientes imersivos é um dos principais focos deste estudo. A elaboração de uma solução metodológica ocorreu por meio da investigação do reconhecimento das etapas genéricas pelas quais passa o processo de autoria de materiais voltados para ambientes imersivos. Diferentes tipos de ferramentas foram testadas para comprovar a efetividade do arcabouço metodológico proposto, dentre eles o OpenSimulator, o Singularity, o Scratch for OpenSim, CmapTools e Celtx. A Tabela 1 resume o ferramental estudado e suas características essenciais. 
Tabela 1 - Tabela das ferramentas estudadas.

\begin{tabular}{|c|c|c|c|c|c|}
\hline Ferramenta & Plataforma & Licença & Aplicação & $\begin{array}{l}\text { Aspectos } \\
\text { positivos }\end{array}$ & $\begin{array}{l}\text { Aspectos } \\
\text { negativos }\end{array}$ \\
\hline CMapTools & $\begin{array}{l}\text { Windows, Linux } \\
\text { e Mac. }\end{array}$ & Freeware & $\begin{array}{l}\text { Para a definição } \\
\text { conceitual do } \\
\text { ambiente. }\end{array}$ & $\begin{array}{l}\text { Permite tratar da não } \\
\text { linearidade presente } \\
\text { nos metaversos. } \\
\text { Tem aspecto } \\
\text { intuitivo. }\end{array}$ & $\begin{array}{l}\text { Dependendo das } \\
\text { exigências da } \\
\text { definição conceitual o } \\
\text { processo pode ser } \\
\text { trabalhoso. }\end{array}$ \\
\hline Celtx & $\begin{array}{l}\text { Windows, } \\
\text { Linux, Mac e } \\
\text { aplicativos } \\
\text { mobile. }\end{array}$ & Freeware & $\begin{array}{l}\text { Para a definição } \\
\text { conceitual do } \\
\text { ambiente. }\end{array}$ & $\begin{array}{l}\text { Trata da roteirização } \\
\text { com variados } \\
\text { objetivos. }\end{array}$ & $\begin{array}{l}\text { Não permite tratar a } \\
\text { não linearidade } \\
\text { presente nos } \\
\text { metaversos. }\end{array}$ \\
\hline $\begin{array}{l}\text { Open } \\
\text { Simulator }\end{array}$ & $\begin{array}{l}\text { Windows, Linux } \\
\text { e Mac. }\end{array}$ & $\begin{array}{l}\text { Open } \\
\text { source. }\end{array}$ & $\begin{array}{l}\text { Servidor para a } \\
\text { hospedagem do } \\
\text { ambiente. }\end{array}$ & $\begin{array}{l}\text { Permite a } \\
\text { implementação do } \\
\text { ambiente de maneira } \\
\text { local com controle } \\
\text { sobre o conteúdo } \\
\text { disponibilizado no } \\
\text { ambiente. }\end{array}$ & $\begin{array}{l}\text { Exige que o } \\
\text { desenvolvedor trate } \\
\text { de configurações para } \\
\text { a disponibilidade do } \\
\text { metaverso. }\end{array}$ \\
\hline Second Life & $\begin{array}{l}\text { Windows, Linux } \\
\text { e Mac. }\end{array}$ & $\begin{array}{l}\text { Software } \\
\text { proprietári } \\
\text { o. }\end{array}$ & $\begin{array}{l}\text { Servidor para a } \\
\text { hospedagem do } \\
\text { ambiente. }\end{array}$ & $\begin{array}{l}\text { Não exige que o } \\
\text { desenvolvedor se } \\
\text { envolva com as } \\
\text { configurações para } \\
\text { disponibilidade do } \\
\text { metaverso. }\end{array}$ & $\begin{array}{l}\text { Possui limitações } \\
\text { etárias para a } \\
\text { utilização. } \\
\text { Podem ser cobradas } \\
\text { taxas dos usuários. }\end{array}$ \\
\hline Singularity & $\begin{array}{l}\text { Windows, Linux } \\
\text { e Mac. }\end{array}$ & $\begin{array}{l}\text { Open } \\
\text { source. }\end{array}$ & $\begin{array}{l}\text { Criação de objetos e } \\
\text { elementos. } \\
\text { Acesso dos usuários } \\
\text { ao ambiente. }\end{array}$ & $\begin{array}{l}\text { Importação e } \\
\text { visualização de } \\
\text { objetos de } \\
\text { repositórios e objetos } \\
\text { multimídia. }\end{array}$ & $\begin{array}{l}\text { Exige mais poder de } \\
\text { processamento em } \\
\text { comparação a outros } \\
\text { viewers. }\end{array}$ \\
\hline $\begin{array}{l}\text { Scratch for } \\
\text { OpenSim }\end{array}$ & $\begin{array}{l}\text { Windows, Linux } \\
\text { e Mac. }\end{array}$ & $\begin{array}{l}\text { Open } \\
\text { source. }\end{array}$ & $\begin{array}{l}\text { Para a manipulação } \\
\text { dos objetos e } \\
\text { elementos criados. }\end{array}$ & $\begin{array}{l}\text { De fácil utilização, } \\
\text { torna a programação } \\
\text { uma tarefa simples. }\end{array}$ & $\begin{array}{l}\text { Limita algumas } \\
\text { possibilidades na } \\
\text { implementação. }\end{array}$ \\
\hline
\end{tabular}

Um desafio que ainda vem sendo observado em parte das pesquisas relacionadas ao tema é a dificuldade que existe no desenvolvimento de conteúdos ou exploração das possibilidades que as ferramentas trazem aos professores. Observando este ponto, as definições do arcabouço metodológico, juntamente com o estudo ferramental, descritos neste artigo buscam uma maneira de facilitar e guiar a autoria de conteúdos educativos para os ambientes imersivos, principalmente quando estão envolvidos conceitos abstratos que demandam modelos visuais para sua melhor compreensão.

Outro desafio deste tipo de ambiente é a falta de controle da interface sobre o usuário. Este aspecto pode desencadear a navegação não direcionada do aluno através dos conteúdos disponibilizados no ambiente sem que este tenha claro quais são as atividades e locais que devem ser explorados para atingir o objetivo da aprendizagem. A partir disso, torna-se necessário a roteirização dos conteúdos para ambientes tridimensionais através do uso de mapas conceituais e posteriormente com uma indicação clara aos avatares sobre quais os caminhos que devem ser seguidos. Esta indicação pode ser feita por meio de implementações que limitem o acesso às salas conforme a evolução do estudante ou ainda de maneira visual, usando setas e numerações, por exemplo.

Por fim, através dos testes com as ferramentas, ficou demonstrado que o arcabouço metodológico descreve os passos para a autoria de conteúdos com foco em ambientes imersivos. A proposta apresenta características genéricas para a autoria, possibilitando que o ferramental específico investigado nesta pesquisa não seja de uso obrigatório ao professor/desenvolvedor, permitindo que este defina os softwares a partir de seu domínio ou aplicabilidade. 
Embora a metodologia definida auxilie na identificação dos passos para o desenvolvimento de conteúdos em ambientes imersivos, ainda são necessários muitos conhecimentos específicos e técnicos para que o professor consiga implantar em sua prática o uso de AVA imersivo. Desta forma, como trabalhos futuros pretende-se investigar a possibilidade de prover através de ferramentas computacionais um ambiente 3D onde apenas a etapa de inserção de conteúdos multimídia no ambiente imersivo seja realizada pelo professor. Para esta finalidade, é necessário que o ambiente 3D de aprendizagem esteja pronto no AVA e o professor apenas coloque seus conteúdos nesse ambiente.

\footnotetext{
${ }^{1}$ Abrange a total liberdade de interação que o avatar apresenta em um ambiente com imersão, característica que este tipo de ambiente traz intrínseco às suas especificações.

${ }^{2}$ Servidor open source para a hospedagem de mundos virtuais. Mais informações em http://opensimulator.org/

${ }^{3}$ Cliente que permite acessar, interagir e editar elementos no metaverso. Mais informações em http://www.singularityviewer.org/

${ }^{4}$ Ferramenta que permite programar animações de maneira fácil e intuitiva e importar códigos para o OpenSimulator baseada na ferramenta Scratch. Mais informações em http://scratch.mit.edu/

${ }^{5}$ Para a roteirização de histórias, filmes, peças teatrais e animações. Mais informações em https://www.celtx.com/

${ }^{6}$ Edição de Mapas Conceituais para a organização de conteúdos. Mais informações em http://cmap.ihmc.us/

${ }^{7}$ Mais informações e acesso em http://secondlife.com/

${ }^{8}$ Existem variados repositórios de objetos e elementos prontos que podem ser inseridos de maneira simples em um ambiente imersivo, o que descomplica o processo de criação.

${ }^{9} \mathrm{O}$ OpenSim Creations pode ser acessado no link http://opensim-creations.com/

${ }^{10}$ Enciclopédia online de criação coletiva. Pode ser acessado pelo link https://pt.wikipedia.org/

${ }^{11}$ Acesso em https://vimeo.com/
}

\section{Agradecimentos}

Agradecimentos ao Programa de Pós Graduação em Computação (PPGCOMP FURG) e à Fundação de Amparo à Pesquisa do Estado do Rio Grande do Sul (FAPERGS).

\section{Referências Bibliográficas}

ÁVILA, Bárbara; AMARAL, ÉRICO M. H.; TAROUCO, Liane. Implementação de Laboratórios Virtuais no metaverso OpenSim. Revista Novas Tecnologias na Educação, V. 11 N 1, julho, 2013.

CONOLE, Grainne. Capturing practice: the role of mediating artefacts in learning design. In: Lockyer, L. et al. (eds). Handbook of Research on Learning Design and Learning Objects. pp.187-207, Hersey, PA, IGI Global, 2008.

FRAGOSO, Suely; ROSÁRIO, Nísia Martins do. Melhor que eu: um estudo das representações do corpo em ambientes gráficos multiusuário on-line de caráter multicultural. Interin, Universidade Tuiuti do Paraná, Curitiba, v. 6, p. 3, 2008.

KHOT, Rohit Ashok; CHOPPELLA, Venkatesh. DISCOVIR: A Framework for Designing Interfaces and Structuring Content for Virtual Labs. IEEE International Conference on Technology for Education, 2011.

LORENZO, Carlos-Miguel; SICILIA, Miguel Ángel; SÁNCHEZ, Salvador. Studying the effectiveness of multi-user immersive environments for collaborative evaluation tasks. Computers \& Education V. 59, 2012.

MCGONIGAL, Jane. Reality is Broken: why games make us better and how they can change the world. New York: Penguin Books, 2011.

MOTA, Fernanda P.; ESPÍNDOLA, Danúbia B.; PINTO, Ivete M.; TUSNSKI, Luis. Um Caso de Uso do Ambiente Virtual de Aprendizagem (Sloodle) no Ensino à Distância. IX Congresso Brasileiro de Ensino Superior a Distância, 2012. 
NASCIMENTO, Lauriza; SPILKER, Maria João. Congresso Virtual no Second Life: Uma Atividade Imersiva na Perspetiva de Alunos do Mestrado em Pedagogia do E-Learning. II Congresso Internacional TIC e Educação, 2012.

NUNES, Felipe Becker; VOSS, Gleizer Bierhalz; HERPICH, Fabrício; MÜHLBEIER, Andreia; POSSOBOM, Camila Cerezer; MEDINA, Roseclea Duarte. Viewers Para Ambientes Virtuais Imersivos: Uma Análise Comparativa Teórico-Prática. Revista Novas Tecnologias na Educação, V. $11 \mathrm{~N}^{0}$ 1, julho, 2013.

PEREIRA, Daniervelin Renata Marques. Phpwebquest e Cmaptools: O Papel da Documentação no Acesso aos Softwares. Revista Texto Livre, N.o 2 vol. 1 outono de 2009.

PETERS, Otto. Didática Do Ensino A Distância. Rio Grande do Sul: Editora Unisinos, 2006.

SCHAF, Frederico M. Arquitetura Modular para Ambientes Virtuais de Ensino de Automação com Suporte à Realidade Mista e Colaboração. Tese de Doutorado em Engenharia Elétrica - UFRGS, RS, 2011.

SCHLEMMER, Eliane; BACKES, Luciana. METAVERSOS: novos espaços para construção do conhecimento. Revista Diálogo Educacional, Curitiba, v. 8, n. 24, p. 519-532, 2008.

SOUZA, Rafael C.; NETO, Francisco M. M.; MUNIZ, Raphael de C. Generic OER Factory: Uma Ferramenta de Autoria para Adaptação dos Recursos Educacionais Abertos aos Novos Ambientes Virtuais de Aprendizagem. RENOTE - Revista Novas Tecnologias na Educação v. 11, n. 3, 2013.

TAROUCO, Liane; ÁVILA, Bárbara; AMARAL, Érico; ZEDNIK, Herik. VEGA - Implementando um Laboratório Virtual Imersivo no OpenSim. Revista Novas Tecnologias na Educação, V. 10 № 1, julho, 2012.

VIEGAS, S.C. Second Life: A New Approach In Professional Education In The Study Of Work Safety. IEEE Latin America Transactions, V. 10, № 1, jan, 2012.

VOSS, Gleizer B.; NUNES, Felipe B.; AMARAL, Érico M. H.; MEDINA, Roseclea D.; TAROUCO, Liane. Utilização do Sloodle para integração de Mundos Virtuais com o Moodle utilizando o OpenSim. Moodle-Moot Brasil, 2013. 